\title{
Second-generation recombinant hemoglobin molecules do not stimulate sphincter of Oddi, gallbladder or duodenal motility in the Australian brush-tailed possum
}

\author{
Shunichi Takahata MD, Hiroyuki Konomi MD, Ann C Schloithe Ad Cert Med Lab Sci, \\ James Toouli MBBS PhD FRACS, Gino TP Saccone PhD
}

\begin{abstract}
S Takahata, H Konomi, AC Schloithe, J Toouli, GTP Saccone. Second-generation recombinant hemoglobin molecules do not stimulate sphincter of Oddi, gallbladder or duodenal motility in the Australian brush-tailed possum. Can J Gastroenterol 2004;18(7):441-448.
\end{abstract}

BACKGROUND: Several studies have investigated the effects of hemoglobin-based oxygen carriers on gastrointestinal motility. Diaspirin cross-linked hemoglobin reduces sphincter of Oddi transsphincteric flow and increases duodenal motility in the Australian brush-tailed possum, effects attributed to nitric oxide (NO) scavenging. Recently, second- generation recombinant hemoglobin molecules with reduced $\mathrm{NO}$ scavenging ability have been developed. AIM: To determine the effects of two second-generation recombinant hemoglobin solutions and the prototype recombinant hemoglobin with high NO binding, on duodenal and biliary motility in the Australian brush-tailed possum.

METHOD: Blood pressure; duodenal, sphincter of Oddi and gallbladder motility; and trans-sphincteric flow were recorded. The effects of recombinant hemoglobin or human serum albumin (control) solutions on these parameters were investigated. Each solution was infused intravenously at $1 \mathrm{~mL} / \mathrm{kg} / \mathrm{min}$ to deliver $250 \mathrm{mg} / \mathrm{kg}$ or $500 \mathrm{mg} / \mathrm{kg}$

RESULTS: Duodenal contraction frequency was stimulated by the high dose of prototype recombinant hemoglobin, but not by a comparable dose of second-generation recombinant hemoglobin. The induced duodenal activity occurred in the later phase of the experimental period. In contrast, biliary motility and trans-sphincteric flow were not altered by any hemoglobin solution. The high dose of all the hemoglobin solutions elevated blood pressure, whereas the low dose solutions did not alter any parameter measured.

CONCLUSION: At the doses studied, the second-generation recombinant hemoglobin with reduced NO binding capacity did not significantly alter duodenal and biliary motility, supporting the need for further studies to evaluate their potential usefulness as blood substitutes.

Key Words: Biliary motility; Diaspirin cross-linked hemoglobin; Duodenal motility; Hemoglobin-based oxygen carrier; Nitric oxide; Recombinant hemoglobin
Les molécules d'hémoglobine recombinante de seconde génération ne stimulent ni le sphincter d'Oddi, ni la vésicule biliaire ni la motilité duodénale chez l'oppossum d'Australie

CONTEXTE : Plusieurs études ont mesuré les effets des transporteurs d'oxygène à base d'hémoglobine sur la motilité gastro-intestinale. L'hémoglobine liée à la diaspirine ralentit le débit trans-sphinctérique à travers le sphincter d'Oddi et stimule la motilité duodénale chez l'oppossum d'Australie, effet attribué au piégeage de l'oxyde nitrique (NO) Récemment, des molécules d'hémoglobine recombinante de seconde génération dotées d'une capa-cité moindre de piégeage du NO ont été mises au point.

OBJECTIF : Déterminer les effets de deux solutions d'hémoglobine recombinante de seconde génération et du prototype d'hémoglobine recombinante doté d'une forte affinité pour le NO sur la motilité duodénale et biliaire chez l'oppossum d'Australie.

MÉTHODE : La tension artérielle, la motilité duodénale, celle du sphincter d'Oddi et de la vésicule biliaire, de même que le débit transsphinctérique ont été enregistrés. Les effets de l'hémoglobine recombinante ou de l'albumine sérique humaine (témoin) en solution sur les paramètres ont aussi été notés. Chaque solution a été administrée par voie intraveineuse à raison de $1 \mathrm{~mL} / \mathrm{kg} / \mathrm{min}$ de façon à générer $250 \mathrm{mg} / \mathrm{kg}$ ou $500 \mathrm{mg} / \mathrm{kg}$.

RÉSULTATS : La fréquence des contractions duodénales a été stimulée par la dose élevée du prototype d'hémoglobine recombinante, mais non par une dose comparable d'hémoglobine recombinante de seconde génération. L'activité duodénale induite s'est manifestée au cours de la phase tardive de l'expérience. En revanche, la motilité biliaire et le débit trans-sphinctérique n'ont pas été influencés par les solutions d'hémoglobine. La dose élevée de toutes les solutions d'hémoglobine a fait augmenter la tension artérielle, alors que les solutions à dose faible n'ont pas modifié les paramètres mesurés.

CONCLUSION : Aux doses étudiées, l'hémoglobine recombinante de seconde génération dotée d'une capacité de fixation moindre au NO n'a pas modifié significativement la motilité duodénale et biliaire, ce qui justifie la conduite d'autres études dans le but d'évaluer leur utilité potentielle à titre de substituts du sang.

Department of General and Digestive Surgery, Centre for Neuroscience and the Centre for Digestive Science, Flinders University, Flinders Medical Centre, Bedford Park, South Australia, Australia

Correspondence: Dr Gino TP Saccone, Department of General and Digestive Surgery, Flinders Medical Centre, Bedford Park,

South Australia, Australia 5042. Telephone +61-8-8204-5223, fax +61-8-8204-5966, e-mail gino.saccone@flinders.edu.au

Received for publication October 9, 2003. Accepted April 27, 2004 
$T_{\mathrm{i}}^{\mathrm{h}}$ he shortage of donated blood and the increasing risk of infections have led to the development of blood substitutes as oxygen carriers. Various types of hemoglobin-based oxygen carriers (HBOC) have been produced $(1,2)$. Chemically or genetically modified hemoglobin solutions have several advantages including compatibility with all blood types and superior storage stability compared with donated human blood $(3,4)$.

A number of studies have reported physiological effects of HBOCs mediated by nitric oxide (NO) scavenging, mainly in the cardiovascular system $(5,6)$. In the gastrointestinal tract, abdominal discomfort, pain, nausea and vomiting have been reported following the application of various HBOC solutions $(7-10)$ and effects on esophageal $(11,12)$ and sphincter of Oddi (SO) motor function $(13,14)$ and gastric emptying $(15)$ have been reported.

Recombinant human hemoglobin $(\mathrm{rHb})$ molecules that display similar oxygen delivery to human hemoglobin have been developed, and are free of infectious agents (16). The prototype $\mathrm{rHb}$ molecule ( $\mathrm{rHb} 1.1$ ) displayed extensive $\mathrm{NO}$ binding capacity (17), but recently developed second-generation $\mathrm{rHb}$ molecules, such as monomer $\mathrm{rHb}$ and $\mathrm{rHb} 2.0$, have markedly reduced $\mathrm{NO}$ scavenging ability (18). For example, rHb2.0 has approximately 20- to 30-fold lower NO scavenging compared with that of rHb1.1 (19). These second-generation molecules display reduced gastric motility and hemodynamic effects $(15,18,19)$.

The effects of the second-generation $\mathrm{rHb}$ on duodenal and biliary motility have not been reported. Therefore, the aims of the present investigation were to compare the effects of three $\mathrm{rHbs}$ with various rates of $\mathrm{NO}$ scavenging on duodenal and biliary motility in anesthetized Australian brush-tailed possums.

\section{METHODS}

Ethical approval for these studies was granted by the Flinders University Animal Welfare Committee, Australia.

\section{Animal preparation}

Adult Australian brush-tailed possums $(n=30)$ of either sex $(1.6 \mathrm{~kg}$ to $3.2 \mathrm{~kg}$ ) were used in the present study. The animals were fasted for $18 \mathrm{~h}$ and anesthesia was induced with intramuscular xylazine (Rompun; $5 \mathrm{mg} / \mathrm{kg}$, Bayer Australia Ltd, Australia) and ketamine (Ketalar, $20 \mathrm{mg} / \mathrm{kg}$, Parke-Davis Pty Ltd, Australia) injections. The left femoral vein was cannulated and a continuous infusion of pentobarbital sodium (Nembutal, $15 \mathrm{mg} / \mathrm{kg} / \mathrm{h}$ to $45 \mathrm{mg} / \mathrm{kg} / \mathrm{h}$, Rhone Merieux Pty Ltd, Australia) was used to maintain anesthesia throughout the experimental period. The animals were intubated through a tracheotomy and mechanically ventilated using a small animal respirator (Phipps and Bird Inc, USA). A constant infusion of saline $(2 \mathrm{~mL} / \mathrm{kg} / \mathrm{h}$ to $4 \mathrm{~mL} / \mathrm{kg} / \mathrm{h})$ was delivered via the left femoral vein. Blood pressure was measured via a catheter in the left femoral artery connected to a pressure transducer (Transpac IV, Abbott Critical Care Systems, Ireland). Animal body temperature was maintained at $37^{\circ} \mathrm{C}$ with a homeothermic blanket (Harvard Apparatus Ltd, United Kingdom).

\section{Measurements of duodenal and biliary motility}

The basic experimental techniques for measuring duodenal and biliary motility have been described previously (14). Intraperitoneal access was gained by a midabdominal incision. An incision was then made in the common bile duct $5 \mathrm{~mm}$ to $10 \mathrm{~mm}$

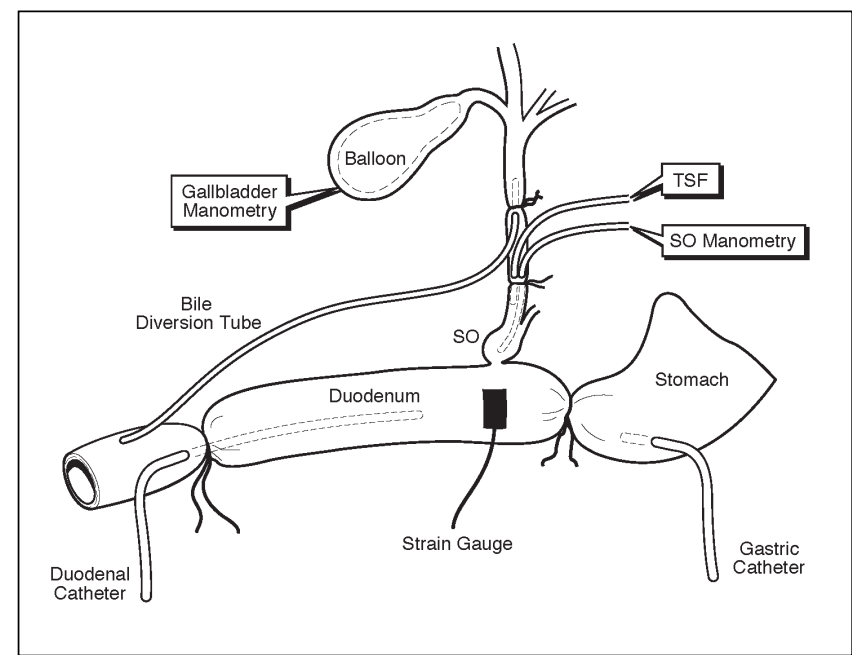

Figure 1) Diagram of the possum preparation used in these studies. Catheters for sphincter of Oddi (SO) manometry, trans-sphincteric flow (TSF) and the gallbladder balloon are shown. The strain gauge to measure duodenal motility was placed opposite the SO. Gastric and duodenal drains are also illustrated

distal to the cystic duct through which three catheters were inserted (Figure 1). One end of a bile diversion tube, a polyvinyl chloride single lumen catheter $(1.52 \mathrm{~mm}$ outside diameter [OD], $0.86 \mathrm{~mm}$ inside diameter [ID], length $25 \mathrm{~cm}$ ), was inserted $2 \mathrm{~mm}$ toward the liver and secured with a ligature. The other end of this catheter was located in the lumen of the distal duodenum, thereby maintaining the enterocirculation of bile salts. The two other catheters, to measure trans-sphincteric flow and SO manometry, were inserted towards the duodenum and secured in position with a ligature.

The trans-sphincteric flow catheter (polyvinyl chloride, $1.52 \mathrm{~mm}$ OD, $0.86 \mathrm{~mm}$ ID, length $40 \mathrm{~cm}$ ), with an end hole, was positioned $2 \mathrm{~mm}$ proximal to the SO. The other end of this catheter was connected to a reservoir containing $20 \mathrm{~mL}$ saline and elevated $10 \mathrm{~cm}$ above the common bile duct, corresponding to physiological bile duct pressure. The reservoir was attached to an isometric force transducer and trans-sphincteric flow was measured gravimetrically as follows. The weight of the reservoir was continuously recorded via the force transducer, which acted as an electromagnetic balance. As trans-sphincteric flow occurred, the weight of the reservoir decreased and the rate of change (slope) represented trans-sphincteric flow. Aliquots of saline $(1 \mathrm{~mL})$ were delivered into the reservoir at regular intervals to maintain a relatively constant inflow (20).

The single lumen manometry catheter (polyethylene, $0.60 \mathrm{~mm}$ OD, $0.20 \mathrm{~mm}$ ID, length $20 \mathrm{~cm}$ ), with a single side hole $1 \mathrm{~mm}$ from the tip, was positioned in the distal segment of the SO. The manometry catheter was connected in series with a low compliance pneumohydraulic capillary infusion system (Arndorfer Medical Specialities, USA) and a pressure transducer (Transpac IV). The manometry catheter was perfused with bubblefree saline at a rate of $0.12 \mathrm{~mL} / \mathrm{min}$. A saline-filled balloon catheter was placed into the gallbladder through a small incision made at the fundus and connected to a pressure transducer.

To measure duodenal contractions, a strain gauge transducer (KFG-1-120-C3-11, Kyowa Electronic Instruments Co Ltd, Japan) embedded in silicon, was attached to the anterior duodenal serosal surface (circumferential orientation) at $1 \mathrm{~cm}$ oral to the 


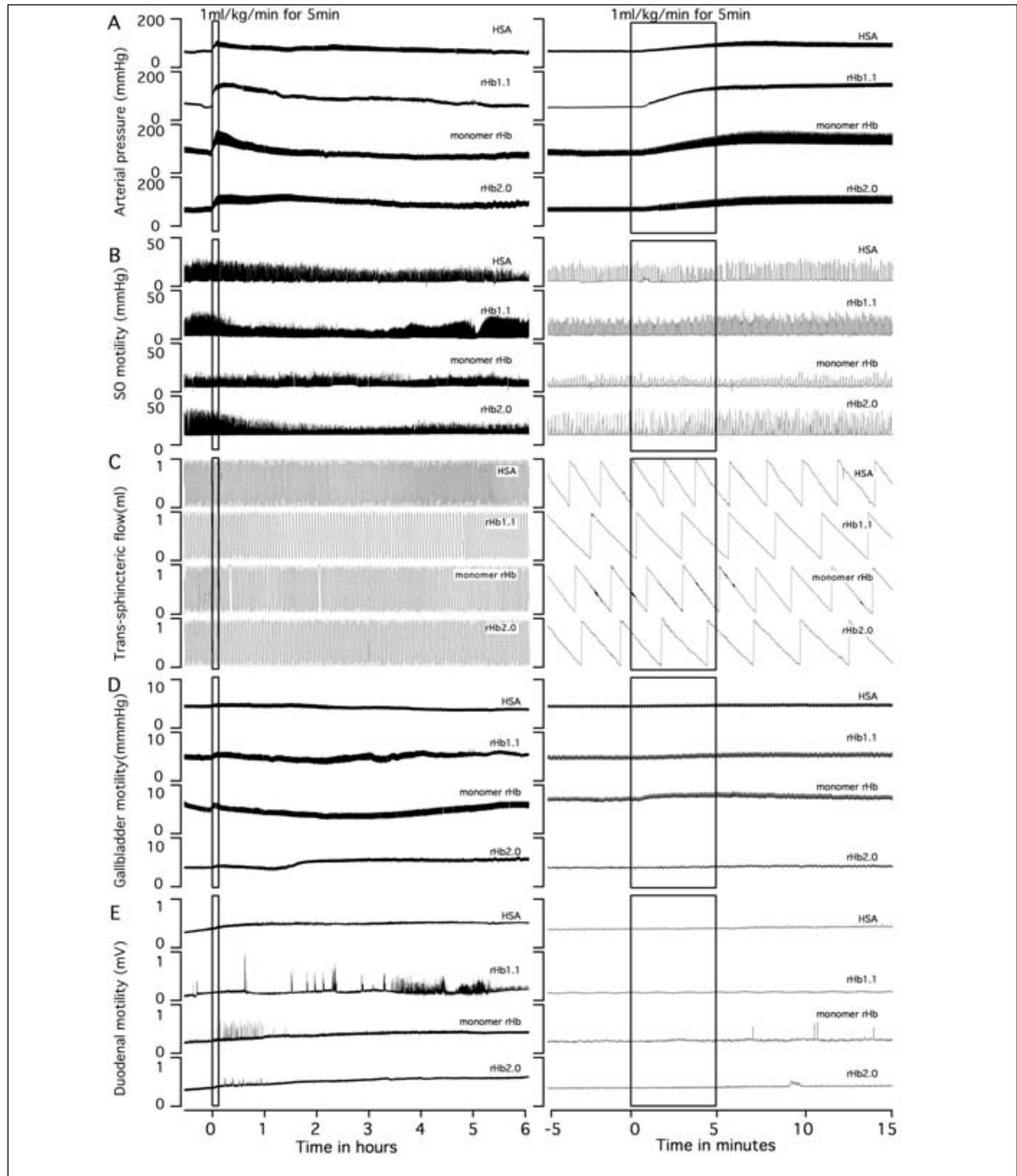

Figure 2) Representative recordings illustrating the effect of $500 \mathrm{mg} / \mathrm{kg}$ infusion of the recombinant human hemoglobin ( $r \mathrm{Hb}$ ) and human serum albumin (HSA) solutions. In each figure, the left panels represent the entire experimental period and the right panels represent an expanded time scale showing the $5 \mathrm{~min}$ period immediately before and the $15 \mathrm{~min}$ after infusion. In each panel, four recordings are presented in the following order: HSA (1st), $r \mathrm{Hb} 1.1$ (2nd), monomer $r \mathrm{Hb}(3 r d)$ and $r \mathrm{Hb} 2.0$ (4th). A Arterial blood pressure: $r \mathrm{Hb}$ infusion of any of the $3 \mathrm{rHb}$ caused a rapid increase in blood pressure. In contrast, $r \mathrm{Hb}$ infusion did not significantly alter sphincter of Oddi (SO) motility (B) or trans-sphincteric flow (C). Infusion of the $r \mathrm{Hb}$ solutions produced inconsistent effects on gallbladder motility (D). No obvious change was observed with $r \mathrm{Hb1}$.1, whereas infusion of monomer $r \mathrm{Hb}$ caused a transient, small increase in motility. In $r \mathrm{Hb} 2.0$ infusion, increased motility was seen at $1.5 \mathrm{~h}$ post-infusion. Infusion of $r \mathrm{Hb} 1.1$ produced a prolonged increase in duodenal contraction frequency, whereas infusion of monomer $r \mathrm{Hb}$ or $r \mathrm{Hb} 2.0$ resulted in smaller transient increases. Infusion of the HSA solutions did not significantly alter duodenal contraction frequency (E) 
SO using n-butyl-cyanoacrylate (Vetbond, 3M Animal Care Products, USA).

Fluctuations in gastric and duodenal pressure can influence $\mathrm{SO}$ motility. To avoid these sources of variability, the pylorus was ligated and a silastic rubber catheter $(3.5 \mathrm{~mm} \mathrm{OD}, 2.8 \mathrm{~mm}$ ID, length $15 \mathrm{~cm}$ ) with several side holes was inserted into the antrum and fixed in position with a ligature to drain the gastric contents and maintain a constant gastric pressure (Figure 1). Similarly, another silastic rubber catheter was inserted in the duodenum, $4 \mathrm{~cm}$ distal to the SO-duodenal junction, towards the $\mathrm{SO}$, via a small incision and secured with a ligature. This catheter served to drain the contents of the resultant pyloric-duodenal segment and maintain a constant pressure.

\section{Data acquisition}

Arterial blood pressure, SO, gallbladder and duodenal motility and trans-sphincteric flow were continuously recorded using a MacLab recording system and Chart 3.5 software (ADInstruments Pty Ltd, Australia).

\section{Experimental protocol}

All preparations displayed spontaneous biliary and duodenal motility. After a 30 min equilibration period, a test dose of 200 ng/kg cholecystokinin octapeptide (CCK-8, Auspep Pty Ltd, Australia) was administered intravenously to confirm that SO, gallbladder and duodenal recordings were satisfactory. The responses to CCK-8 were short-lived with all parameters returning to baseline within $15 \mathrm{~min}$ of administration. An additional $60 \mathrm{~min}$ re-equilibration period was allowed before $\mathrm{rHb}$ or human serum albumin (HSA) solution, iso-oncotic to rHb2.0 (Baxter Healthcare Corporation, USA), administration.

One of three $\mathrm{rHb}$ solutions ( $\mathrm{rHb} 1.1$, monomer $\mathrm{rHb}$ or $\mathrm{rHb} 2.0$, Baxter Healthcare Corporation), 10\% v/v or HSA was infused at $1 \mathrm{~mL} / \mathrm{kg} / \mathrm{min}$ for $2.5 \mathrm{~min}$ to deliver $250 \mathrm{mg} / \mathrm{kg}$ or for $5 \mathrm{~min}$ to deliver $500 \mathrm{mg} / \mathrm{kg}$ clinically relevant doses recommended by the supplier ( $\mathrm{n}=5$ animals/dose/rHb solution). These doses were selected based on the results of preliminary studies. The $\mathrm{rHb}$ molecules display a range of $\mathrm{NO}$ binding: high for $\mathrm{rHb} 1.1$, low for monomer $\mathrm{rHb}$ and, in the case of $\mathrm{rHb} 2.0$, $\mathrm{NO}$ binding equivalent to hemoglobin. All parameters were recorded for $360 \mathrm{~min}$ following infusion and the animals were then euthanized by an overdose of pentobarbitone (Lethabarb, Virbac Australia Pty Ltd, Australia) at the end of the protocol.

\section{Data and statistical analysis}

Data were analyzed at $15 \mathrm{~min}$ intervals from the $30 \mathrm{~min}$ period immediately before the commencement of infusion of $\mathrm{rHb}$ or HSA solution to $360 \mathrm{~min}$ postinfusion. Mean arterial blood pressure $(\mathrm{mmHg})$, duodenal contraction frequency (contractions $/ 15 \mathrm{~min})$, trans-sphincteric flow $(\mu \mathrm{l} / \mathrm{s})$, SO basal pressure $(\mathrm{mmHg})$ and area under the curve of phasic contractions $(\mathrm{mmHg} \bullet \mathrm{s})$ for SO and gallbladder recordings were calculated using Chart 3.5 software. Group data were expressed as mean \pm SEM. All data were tested for normality. For normally distributed data, statistical comparison of rHbs and HSA data was calculated using repeated measures ANOVA, with the averaged preinfusion responses used as a covariate. For data that were not normally distributed, nonparametric analysis was performed, eg, Friedman, Kruskal-Wallis and Mann-Whitney test (SPSS 9.0.1, SPSS Inc, USA) and $\mathrm{P}<0.05$ was considered statistically significant.

\section{RESULTS}

Administration of second-generation $\mathrm{rHb}$ molecules enhanced blood pressure with little to no effect on biliary and duodenal motility. Figure 2 illustrates typical recordings of each parameter following infusion of $500 \mathrm{mg} / \mathrm{kg}$ of HSA, rHb1.1, monomer $\mathrm{rHb}$ or $\mathrm{rHb} 2.0$ solutions. Group data representing each parameter for all solutions are shown in Figure $3(500 \mathrm{mg} / \mathrm{kg})$ and Figure 4 (250 mg/kg).

\section{Mean arterial blood pressure}

Infusion of $500 \mathrm{mg} / \mathrm{kg}$ of $\mathrm{rHb}$ solutions (first- and secondgeneration molecules) resulted in an elevated mean arterial blood pressure; however, the peak change induced by the first generation molecules were higher than that of the secondgeneration molecules. This increase in blood pressure persisted for at least $1 \mathrm{~h}$ and had an onset within $1 \mathrm{~min}$ after the infusion commenced, whereas infusion of HSA did not significantly change blood pressure (Figure 3A). Of the $\mathrm{rHb}$ solutions infused, rHb1.1 produced the greatest peak increase in blood pressure and maintained an elevated blood pressure for most of the experimental period compared with the HSA infusion. Monomer $\mathrm{rHb}$ infusion produced a significant increase in blood pressure for only $30 \mathrm{~min}$ to $45 \mathrm{~min}$ after infusion began, whereas infusion of $\mathrm{rHb} 2.0$ resulted in a prolonged elevation for the entire experimental period, with peak elevation intermediate between that produced by $\mathrm{rHb} 1.1$ and monomer $\mathrm{rHb}$, compared with HSA solution (Figure 3A).

Infusion of the low dose $(250 \mathrm{mg} / \mathrm{kg}) \mathrm{rHb} 1.1$, monomer $\mathrm{rHb}$ or $\mathrm{rHb} 2.0$ solutions failed to significantly alter blood pressure, compared with the HSA infusion (Figure 4A).

\section{Duodenal motility}

Infusion of the high dose $(500 \mathrm{mg} / \mathrm{kg}) \mathrm{rHb} 1.1$ solution stimulated duodenal contractile activity which was evident in the later phase of the experimental period (210 min to $300 \mathrm{~min}$ postinfusion) compared with HSA infusion (Figure 3B). In contrast, monomer $\mathrm{rHb}$ and $\mathrm{rHb} 2.0$ failed to significantly alter duodenal contraction frequency. Similarly, infusion of the low dose (250 mg/kg) rHb solutions did not significantly influence duodenal motility compared with the HSA infusion (Figure 4B).

SO motility, trans-sphincter flow and gallbladder motility Infusion of the high and low doses of each $\mathrm{rHb}$ solution failed to significantly alter $\mathrm{SO}$ or gallbladder motility compared with HSA infusion (Figure 3C-F, Figure 4C-F).

\section{DISCUSSION}

The present study demonstrates for the first time that infusion of second-generation $\mathrm{rHb}$ molecules with reduced $\mathrm{NO}$ binding capacity, in contrast to first generation $\mathrm{rHb}$ molecules, have no significant effects on SO, gallbladder or duodenal motility and trans-sphincteric flow when compared with HSA infusion.

The first generation HBOCs had a number of undesirable side effects. These included renal toxicity, activation of inflammatory responses, systemic vasoconstrictions and increased esophageal, duodenal and SO motility $(8,10,12,14,21)$. Several side effects were attributed to the $\mathrm{NO}$ binding effect of these molecules. The recently developed second-generation HBOC, rHb2.0, had NO binding comparable to that of hemoglobin. Our data indicated that intravenous administration of this molecule did not influence SO, gallbladder or duodenal motility. 


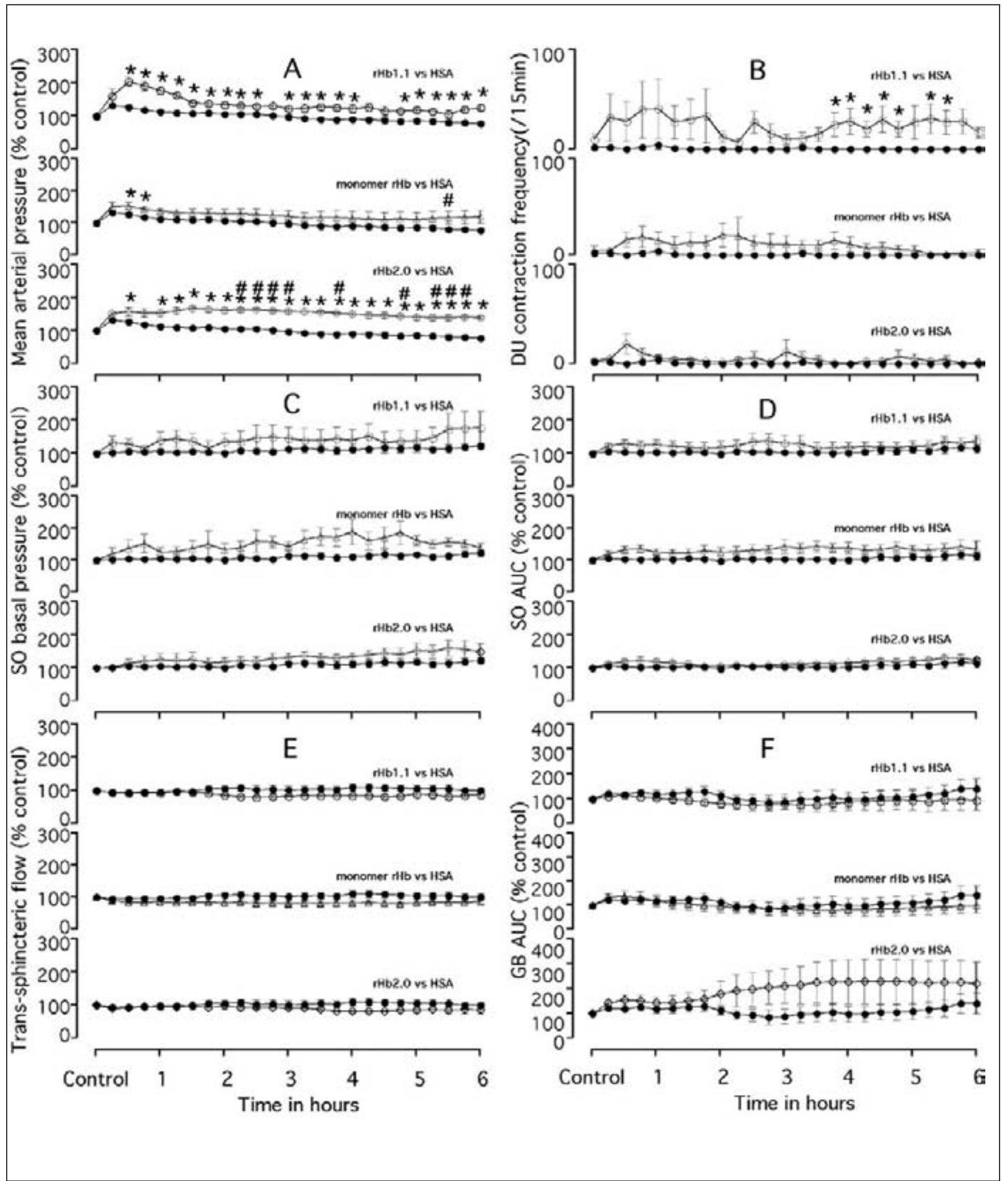

Figure 3) Group data (mean \pm SEM; $n=5$ per group) illustrating the responses to intravenous administration of recombinant human hemoglobin $(\mathrm{rHb})(500 \mathrm{mg} / \mathrm{kg})$ compared with human serum albumin (HSA) infusion. In each panel, data are presented in the following order: top, $r \mathrm{Hb1.1}$ (open circle) vs HSA (closed circle); middle, monomer (open triangle) vs HSA (closed circle); and bottom, rHb2.0 (open diamond) vs HSA (closed circle). Infusion of $r \mathrm{Hb} 1.1$ or $r \mathrm{Hb} 2.0$ produced a significant increase in mean arterial pressure for most of the experimental period. A Infusion of the monomer $\mathrm{rHb}$ increased blood pressure $30 \mathrm{~min}$ to $60 \mathrm{~min}$ after infusion. B Infusion of $r \mathrm{Hb} 1.1$, but not monomer $r \mathrm{Hb}$ or $r \mathrm{Hb} 2.0$, significantly increased duodenal (DU) contraction frequency between $4 \mathrm{~h}$ and $6 \mathrm{~h}$ following infusion. $\mathrm{rHb}$ infusion did not significantly change sphincter of Oddi (SO) basal pressure (C), SO area under the curve (AUC) (D), trans-sphincteric flow (E) and gallbladder (GB) AUC (F), compared with HSA. $* P<0.05$ compared with HSA group; $\mathrm{P}<0.05$ compared with $r \mathrm{Hb} 1.1$ group 


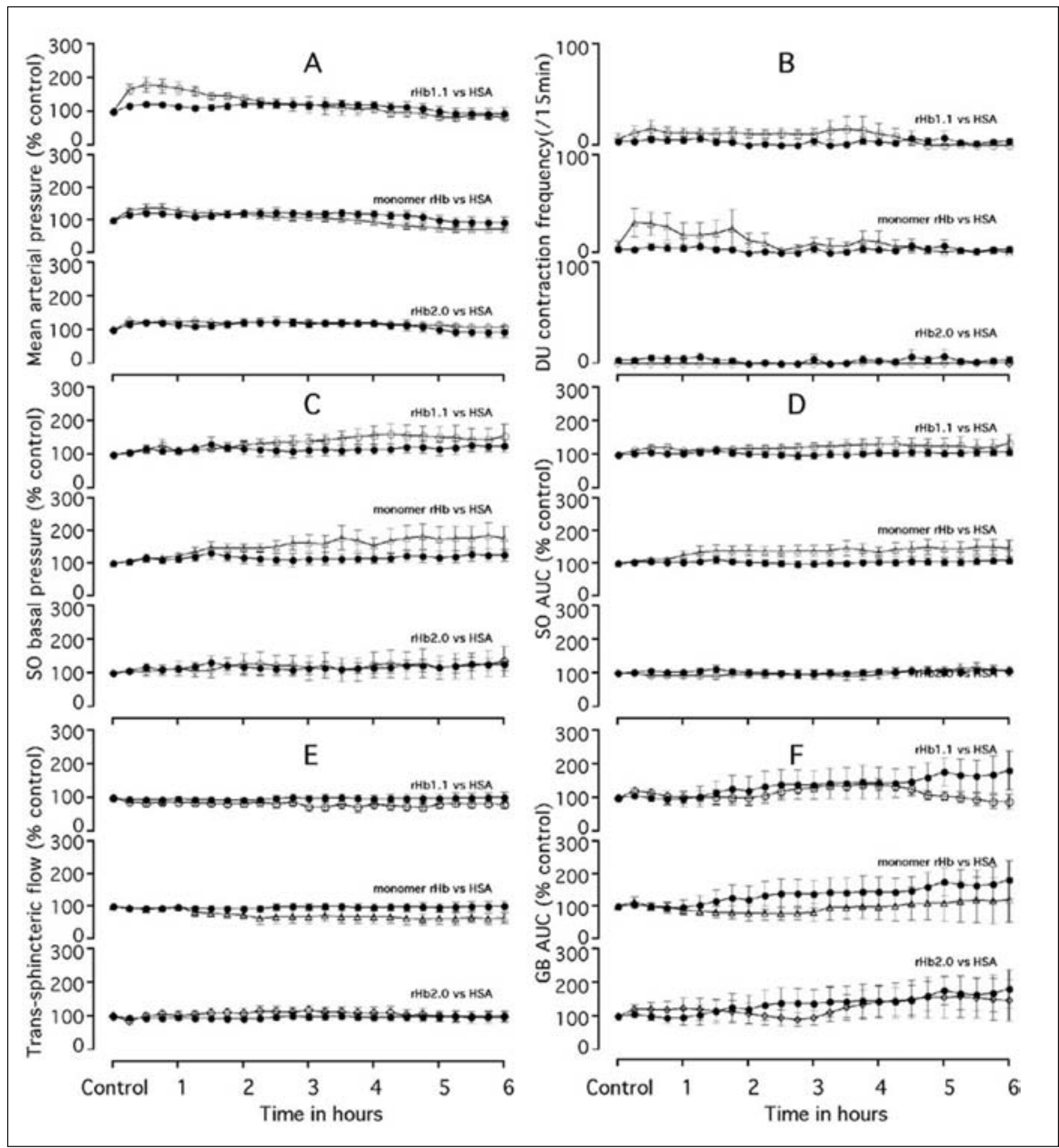

Figure 4) Group data (mean \pm SEM; $n=5$ per group) illustrating the responses to intravenous administration of recombinant human hemoglobin $(r \mathrm{Hb})(250 \mathrm{mg} / \mathrm{kg})$ compared with human serum album (HSA) infusion. In each panel, data are presented in the following order; top, $r \mathrm{Hb} 1.1$ (open circle) vs HSA (closed circle); middle, monomer (open triangle) vs HSA (closed circle); and bottom, rHb2.0 (open diamond) vs HSA (closed circle). $r \mathrm{Hb}$ infusion failed to significantly alter mean arterial pressure (A) duodenal (DU) contraction frequency (B), sphincter of Oddi (SO) basal pressure (C), SO area under the curve (AUC) (D), trans-sphincteric flow (E) or gallbladder (GB) AUC (F)

A human study (9) with the prototype $\mathrm{rHb}(\mathrm{rHb} 1.1)$ reported that $68 \%$ of the volunteers experienced gastrointestinal symptoms including nausea, vomiting, diarrhea, dysphagia and abdominal pain. We also demonstrated that the first generation HBOC molecule, diaspirin cross-linked hemoglobin (DCLHb), had a stimulatory effect on possum duodenal motility over $5 \mathrm{~h}$ (14). In the present series, $\mathrm{rHb} 1.1$ also caused prolonged excitation of duodenal contraction. This action may explain the side effects experienced by human subjects given rHb1.1. The second-generation rHbs with lower NO binding ability 
produced no significant effects on the duodenum. These findings are consistent with the role of $\mathrm{NO}$ as an inhibitory neurotransmitter in the gut (22).

No rHbs investigated in the present study significantly altered possum $\mathrm{SO}$ or gallbladder motility. This contrasts with a previous study (13) in the American opossum where administration of $\mathrm{rHb} 1.1$ increased $\mathrm{SO}$ motility; this may reflect a species difference effect. Our results are important in that we have previously shown that hyperstimulation of the SO leads to pancreatitis in the Australian brush-tailed possum (23). Hyperamylasemia or mild acute pancreatitis has been reported in humans following the administration of DCLHb or $\mathrm{rHb} 1.1$ (24-26). SO stimulation may be a possible mechanism for the induction of pancreatitis in these studies.

With regard to gallbladder motility, we noted variable changes following the administration of $\mathrm{rHb}$ and HSA solutions. Similar variability was observed in our previous study with DCLHb (14). Several patterns of change in gallbladder motility, including acute transient excitation, late sustained excitation, inhibition and no change, were recorded. For $\mathrm{rHb} 1.1$, these variable results may be derived from complex interactions relating to $\mathrm{NO}$ binding and/or the possible production of endothelins in the gallbladder, due to handling of the organ. Other factors, however, may be involved because rHb2.0-treated animals displayed an increased gallbladder activity, particularly from $3 \mathrm{~h}$ to $6 \mathrm{~h}$ postinfusion, although there was considerable variability within this group (Figure 3F). Endothelins have been shown to induce gallbladder contraction $(27,28)$ and have been implicated in DCLHb's cardiovascular effects (5,29-31). An alternative explanation may be the variable action of $\mathrm{NO}$ on the gastrointestinal tract. Both inhibitory and excitatory effects have been attributed to NO in the gastrointestinal tract $(32,33)$. For example, Alcon et al (34) reported NO had excitatory or inhibitory effects on the guinea pig gallbladder depending on the status of oxidative

\section{REFERENCES}

1. Chang TM. Oxygen carriers. Curr Opin Investig Drugs 2002;3:1187-90.

2. Moore EE. Blood substitutes: The future is now. J Am Coll Surg 2003;196:1-17.

3. Gould SA, Moss GS. Clinical development of human polymerized hemoglobin as a blood substitute. World J Surg 1996;20:1200-7.

4. Creteur J, Sibbald W, Vincent JL. Hemoglobin solutions - not just red blood cell substitutes. Crit Care Med 2000;28:3025-34.

5. Schultz SC, Grady B, Cole F, Hamilton I, Burhop K, Malcolm DS. A role for endothelin and nitric oxide in the pressor response to diaspirin cross-linked hemoglobin. J Lab Clin Med 1993;122:301-8.

6. Sharma AC, Singh G, Gulati A. Role of NO mechanism in cardiovascular effects of diaspirin cross-linked hemoglobin in anesthetized rats. Am J Physiol 1995;269:H1379-88.

7. Amberson WR, Jennings JJ, Rhode CM. Clinical Experience with hemoglobin-saline solutions. J Appl Physiol 1949;1:469-89.

8. Savitsky JP, Doczi J, Black J, Arnold JD. A clinical safety trial of stroma-free hemoglobin. Clin Pharmacol Ther 1978;23:73-80.

9. Viele MK, Weiskopf RB, Fisher D. Recombinant human hemoglobin does not affect renal function in humans: Analysis of safety and pharmacokinetics. Anesthesiology 1997;86:848-58.

10. Jahr JS, Nesargi SB, Lewis K, Johnson C. Blood substitutes and oxygen therapeutics: An overview and current status. Am J Ther 2002;9:437-43.

11. Murray JA, Ledlow A, Launspach J, Evans D, Loveday M, Conklin JL. The effects of recombinant human hemoglobin on esophageal motor functions in humans. Gastroenterology 1995;109:1241-8.

12. Conklin JL, Murray J, Ledlow A, et al. Effects of recombinant human hemoglobin on motor functions of the opossum esophagus. J Pharmacol Exp Ther 1995;273:762-7. stress. Furthermore, because of the long duration of our experiments, direct and indirect effects may influence the parameters measured. Thus, these various mechanisms may interact and their relative contribution could dictate the final motor response observed. Because of the complex interactions that can potentially occur in vivo the precise mechanisms underlying our findings are unclear.

Infusion of $\mathrm{rHb} 2.0$ solution induced a rapid elevation in blood pressure which was sustained for at least $6 \mathrm{~h}$. The duration of this response was greater than that observed with the other $\mathrm{rHb}$ tested and may reflect a longer biological half-life of this molecule. The reason for sustained elevation with rHb2.0 is still unclear, however, it may be species-specific. In other species, infusion of $\mathrm{rHb2} .0$ has been noted to increase cardiac output (M Doyle, personal communication). This finding suggests that, at least in the Australian brush-tailed possum, the mechanism(s) responsible for elevated blood pressure may not be related to NO scavenging or that the low $\mathrm{NO}$ binding capacity of the second-generation $\mathrm{rHb}$ molecules is still sufficient to influence the cardiovascular system.

\section{CONCLUSIONS}

rHbs with reduced $\mathrm{NO}$ binding capacity increase blood pressure without duodenal and biliary motility effects. These findings suggest that the second-generation $\mathrm{rHbs}$ do not display significant gastrointestinal or biliary side effects; however, further studies are required to evaluate their potential usefulness as blood substitutes.

ACKNOWLEDGEMENTS: This work was supported by Baxter Healthcare Corporation (grant in aid) and NH and MRC of Australia (grant \#102133). The technical assistance of Mr A Citti, and the cooperation of the National Parks and Wildlife Services of South Australia are acknowledged. We thank M Doyle and M Schick for their useful discussion.
13. Cullen JJ, Conklin JL, Murray J, Ledlow A, Rosenthal G. Effects of recombinant human hemoglobin on opossum sphincter of Oddi motor function in vivo and in vitro. Dig Dis Sci 1996;41:289-94.

14. Konomi H, Woods CM, Meedeniya AC, Giles LC, Toouli J, Saccone GTP. Effects of diaspirin cross-linked hemoglobin on motor function of the duodenum and biliary system in the Australian brush-tailed possum in vivo. J Pharmacol Exp Ther 2001;296:1067-73.

15. Hartman JC, Argoudelis G, Doherty D, Lemon D, Gorczynski R. Reduced nitric oxide reactivity of a new recombinant human hemoglobin attenuates gastric dysmotility. Eur J Pharmacol 1998;363:175-8.

16. Looker D, Abbott-Brown D, Cozart P, et al. A human recombinant haemoglobin designed for use as a blood substitute. Nature 1992;356:258-60.

17. Rioux F, Drapeau G, Marceau F. Recombinant human hemoglobin (rHb1.1) selectively inhibits vasorelaxation elicited by nitric oxide donors in rabbit isolated aortic rings. J Cardiovasc Pharmacol 1995;25:587-94.

18. Doherty DH, Doyle MP, Curry SR, et al. Rate of reaction with nitric oxide determines the hypertensive effect of cell-free hemoglobin. Nat Biotechnol 1998;16:672-6.

19. Resta TC, Walker BR, Eichinger MR, Doyle MP. Rate of NO scavenging alters effects of recombinant hemoglobin solutions on pulmonary vasoreactivity. J Appl Physiol 2002;93:1327-36.

20. Saccone GT, Liu YF, Thune A, Harvey JR, Baker RA, Toouli J. Erythromycin and motilin stimulate sphincter of Oddi motility and inhibit trans-sphincteric flow in the Australian possum. Naunyn Schmiedebergs Arch Pharmacol 1992;346:701-6.

21. Zuckerman SH, Doyle MP, Gorczynski R, Rosenthal GJ. Preclinical 
biology of recombinant human hemoglobin, rHb1.1. Artif Cells Blood Substit Immobil Biotechnol 1998;26:231-57.

22. Konturek SK, Konturek PC. Role of nitric oxide in the digestive system. Digestion 1995;56:1-13.

23. Chen JWC, Thomas, Woods CM, Schloithe AC, Toouli J, Saccone GT. Sphincter of Oddi dysfunction produces acute pancreatitis. Gut 2000;47:539-45.

24. O'Hara JF, Tetzlaff JE, Sintean ME, Mascha EJ, Schubert A. Diaspirin cross-linked hemoglobin increases serum amylase in humans postoperatively. Anesth Analg 1998;86:143S.

25. Hayes JK, Stanley TH, Lind GH, East K, Smith B, Kessler K. A double-blind study to evaluate the safety of recombinant human hemoglobin in surgical patients during general anesthesia. J Cardiaothorac Vasc Anesth 2001;15:593-602.

26. Schubert A, O'Hara JF Jr, Przybelski RJ, et al. Effect of diaspirin crosslinked hemoglobin (DCLHb HemAssist) during high blood loss surgery on selected indices of organ function. Artif Cells Blood Substit Immobil Biotechnol 2002;30:259-83

27. Al-Jiffry BO, Menadue M, Oliver J, Thomas A, Toouli J, Saccone GTP. Endothelins in gallbladder tissue are elevated in acalculus acute cholecystitis. Gastroenterol 2002;122:A440. (Abst)

28. Al-Jiffry BO, Shaffer EA, Woods CM, et al. Endogenous endothelin increases gallbladder tone and leads to acute cholecystitis in the Australian possum. Neurogastroenerol Motil 2004; $16: 125-33$

29. Gulati A, Singh R, Chung SM, Sen AP. Role of endothelinconverting enzyme in the systemic hemodynamics and regional circulatory effects of proendothelin-1 (1-38) and diaspirin crosslinked hemoglobin in rats. J Lab Clin Med 1995;126:559-70.

30. Gulati A, Sharma AC, Singh R. Role of endothelin in the cardiovascular effects of diaspirin cross-linked and stroma reduced hemoglobin. Crit Care Med 1996;24:137-47.

31. Bone HG, Schenarts PJ, Booke M, et al. Oxalated pyridoxalated hemoglobin polyoxyethylene conjugate normalizes the hyperdynamic circulation in septic sheep. Crit Care Med $1997 ; 25: 1010-8$

32. Saha JK, Hirano I, Goyal RK. Biphasic effect of SNP on opossum esophageal longitudinal muscle: Involvement of cGMP and eicosanoids. Am J Physiol 1993;265:G403-7.

33. Holzer P, Lippe IT, Tabrizi AL, Lenard L Jr, Bartho L. Dual excitatory and inhibitory effect of nitric oxide on peristalsis in the guinea pig intestine. J Pharmacol Exp Ther 1997;280:154-61.

34. Alcon S, Morales S, Camello PJ, et al. A redox-based mechanism for the contractile and relaxing effects of $\mathrm{NO}$ in the guinea-pig gall bladder. J Physiol 2001;532:793-810. 


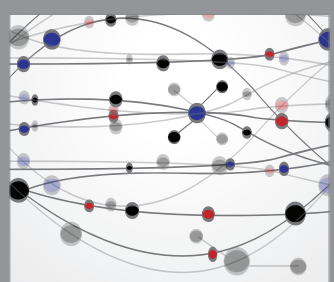

The Scientific World Journal
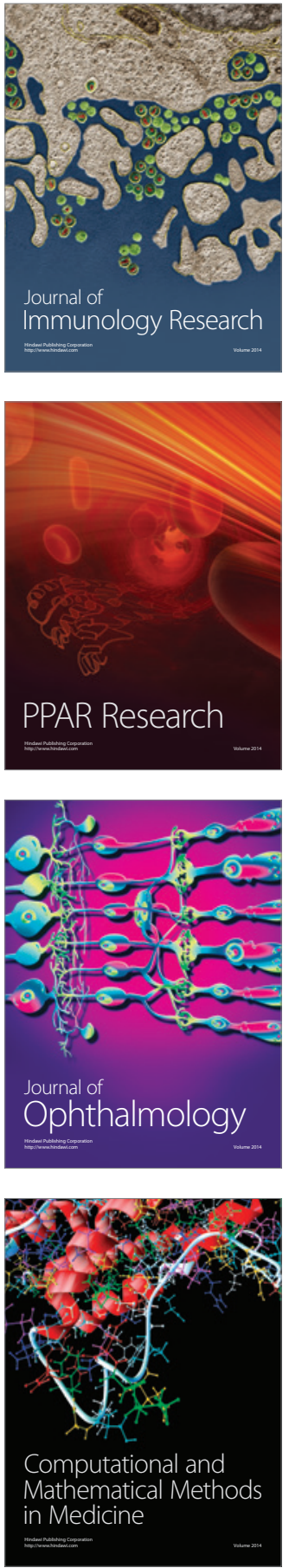

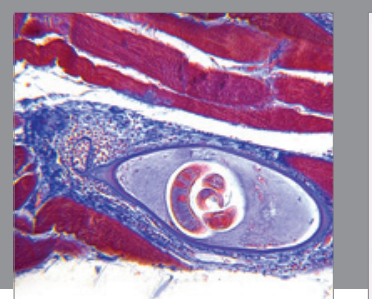

Gastroenterology Research and Practice

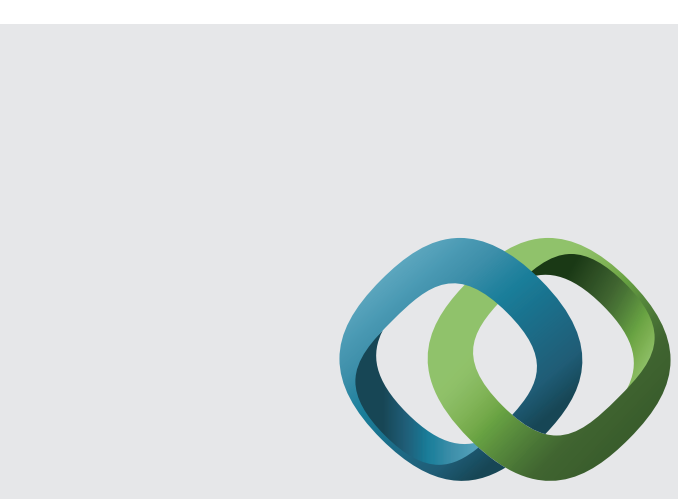

\section{Hindawi}

Submit your manuscripts at

http://www.hindawi.com
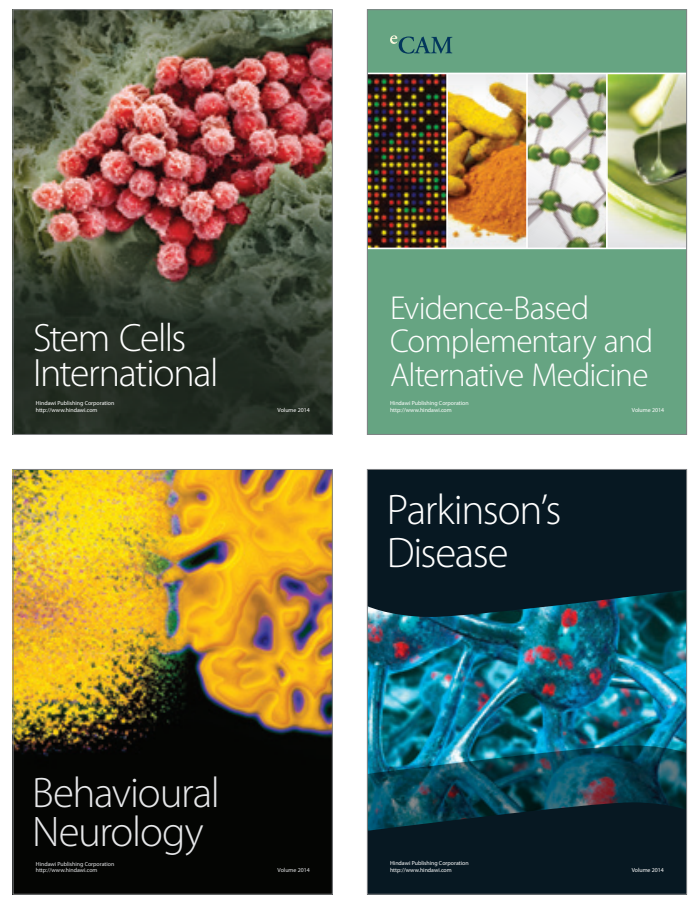
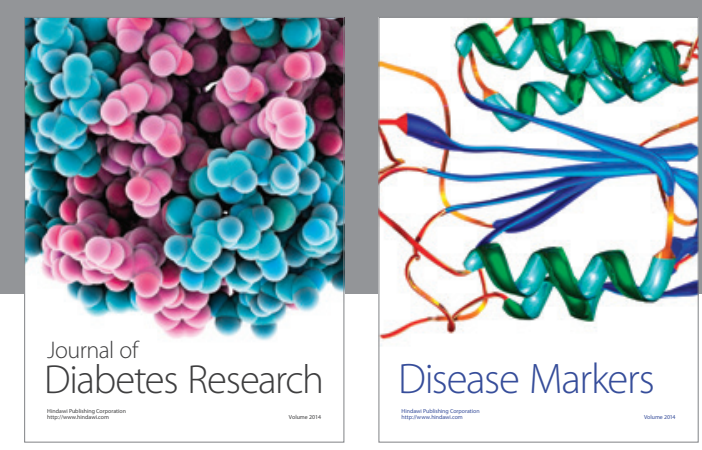

Disease Markers
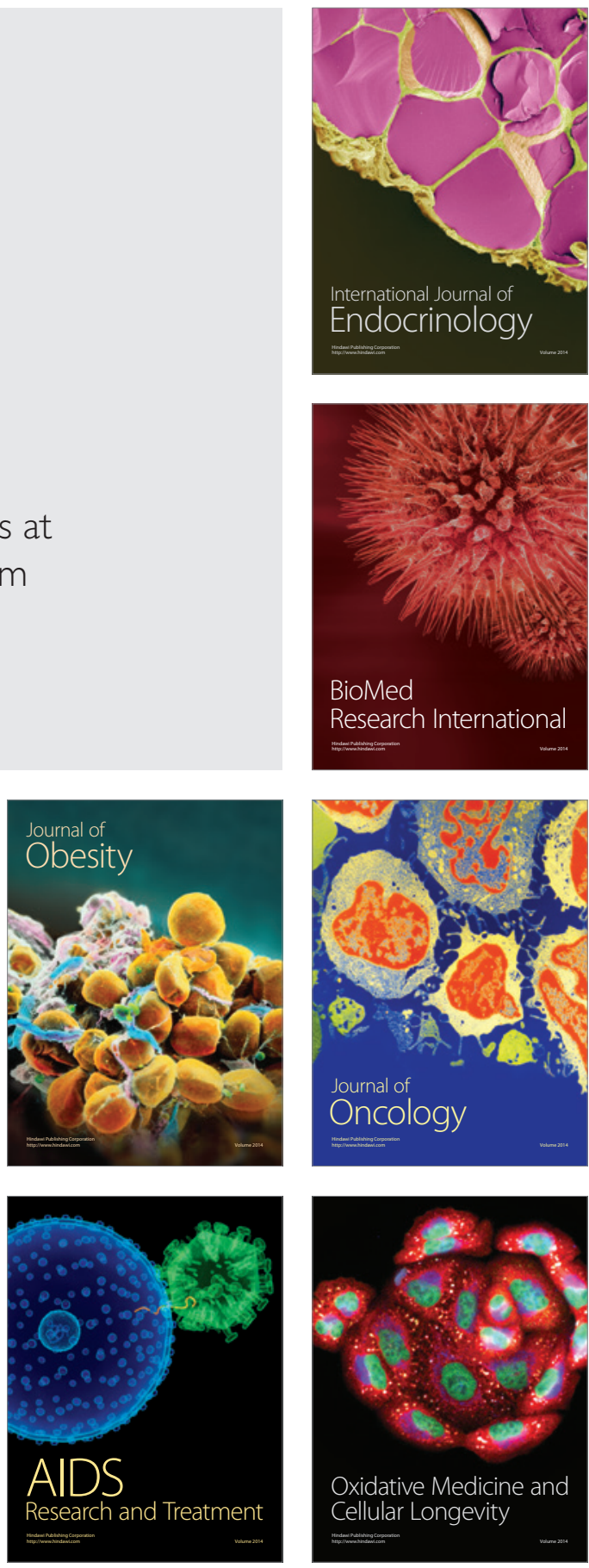